\title{
Jean Jacques Rousseau and Human Enhancement
}

\section{Kusmaryanto $\mathrm{CB}^{*}$}

Graduate School, Sanata Dharma University, Indonesia

*Corresponding author: Carolus Boromeus Kusmaryant, Graduate School, Sanata Dharma University, Jln. Kaliurang Km. 7, Yogyakarta, 55281, Indonesia, Tel: +6281328888911; Email: kusmaryanto@gmail.com

\section{Conceptual Paper}

Volume 4 Issue 3

Received Date: July 12, 2021

Published Date: August 16, 2021

DOI: $10.23880 /$ abca-16000193

\section{Abstract}

Human enhancement is one of the hottest bioethical debates because the two parts have strong foundation on their arguments. Human enhancement is both naturally and technologically. Many people agree upon natural human enhancement because it is part of human dignity. Technological human enhancement spark debates pros and cons. We will learn from Jean-Jacques Rousseau to inspire our discussion. We will use Rousseau's famous statement, "the faculty of self-improvement" in developing argument to arrive in the final conclusion.

Keywords: Enhancement; Freedom; Human Dignity; Human Enhancement; Jean-Jacques Rousseau; Naturalness; Reason; Self-Improvement; Treatment

\section{Human Enhancement}

One of the most fascinating fruits of biological technologies is human enhancement. The possibilities of human enhancement seem no limit because of so many developments and inventions in biology, combined with many other technological inventions. With genetic engineering and plastic surgeries there are many possibilities intervention for the benefit of human beings: therapy, reconstruction, enhancement, modification, alteration, and manipulation. Most of us agree on the reconstruction and therapy of human body because it restores human nature. Most of us also agree to refuse the modification, alteration, and manipulation of human body because it contrary to the human nature. The most debatable is human enhancement.

There are many ways to enhance human beings through plastic surgery, nanotechnology, biotechnology, drugs, hormones, information technology, cognitive science and many more. The general goals of human enhancement are to improve human performance or augmentation of human capabilities by modifying and/or add to the traits or abilities a person is born with. Through new technology, human can be enhanced physically, emotionally, cognitively, and morally.

What is the definition of human enhancement? There are many answers of this question. Marianne Talbot said, "An intervention is an enhancement if and only if it is motivated by the desire to improve some characteristic or condition beyond that which is required for good health or normal functioning" [1]. Talbot make sharp distinction between improvement and good health/normal functioning. In this sense, he makes clear distinction between therapy and enhancement/ improvement. In the real practices, it is not always easy to make distinction between therapy and enhancement. A patient who had a fatal accident with broken nose, he may ask his plastic surgeon to make his nose better appearance. Is it a reconstruction or enhancement? It is not clear.

Giubilini A, et al. [2] make definition more technically, "In bioethics the term 'human enhancement' refers to any kind of genetic, biomedical, or pharmaceutical intervention aimed at improving human dispositions, capacities, and wellbeing, even when there is no pathology to be treated." Giubilini A, et al. [2] explained what kind of intervention which can be classified as enhancement: improvement of human 
disposition, capacities, and well-beings. Enhancement can be made not only for health reason but for well-being reason.

Buchanan A, et al. [3] make definition based closely on medical sciences, "a deliberate intervention, applying biomedical science, which aims to improve an existing capacity that most or all normal human beings typically have, or to create a new capacity, by acting directly on the body or the brain" [3].

In fact, a long history of humanity, human beings always seek to enhance themselves throughout their lives. Improving themselves is part of human desire and nature. By studying hard, human enhance their capacity to think. By exercises, human enhance their body power. By good diets, human enhance their health. By making up, woman enhance their appearance. In the level animal dan crops, humans have manipulated animal's traits traditionally by controlling breeding and selecting offspring to have better livestock. Only animals or crops that have desirable characters will breed so that farmers have only good quality of livestock and crops.

Enhancement is the nature of human beings or even all living beings. At the root of Darwin's theory of evolution is the capacity of self-enhancement or self-improvement so that step by step comes out many living beings as we know today. In other words, human enhancement or human improvement is done naturally and by nature itself.

If nature makes enhancement and it is done naturally, so what, if anything, distinguishes these accepted methods of enhancement from those modern enhancement that cause moral concern? In this case, certainly there is pro and cons on modern human enhancement.

At the center of the ethical debates on human enhancement are human dignity, human nature, personhood, neutrality, and in some more specifics cases about the clear border between treatment and enhancement, between health and illness [4]. In this article we will focused on human dignity and human nature according to Jean-Jacques Rousseau.

\section{Jean Jacques Rousseau on Self-Enhancement}

Jean-Jacques Rousseau (1712-1778) was born in the independent Calvinist city-state of Geneva, Switzerland. He was a political philosopher, writer, and composer. He influenced throughout Europe including the French Revolution and the development of modern political, economic, and educational thoughts. We can trace Rousseau's philosophical influences on Immanuel Kant especially in the Kant's idea of the categorical imperative which we can find in the Groundwork of the Metaphysic of Morals.

Although Rousseau didn't use term human dignity, he laid the basic foundations of the concept of human dignity. For Rousseau, human beings are endowed with freedom and ratio which become the foundation of human dignity. Rousseau's concern is to find a way of preserving human freedom and self-preservation [5]. The differences between animal dan human beings are on human freedom and reason. Animal act only according to nature but human being-with his freedom-can act according to his freedom and reason. Rousseau said, "In any animal I see nothing but an ingenious machine to which nature has given senses in order for it to renew its strength and to protect itself, to a certain point, from all that tends to destroy or disturb it. I am aware of precisely the same things in the human machine, with the difference that nature alone does everything in the operations of an animal, whereas man contributes, as a free agent, to his own operations. The former chooses or rejects by instinct and the later by an act of freedom" [5].

Since only human beings have the reason and freedom it is only human being who has the capacity to choose or to reject impulse from outside [5]. For Rousseau, human reason plays important role in human action because with it, human being can criticize his own position or his standing point in order to correct and improve his capacity to think and to act. Improving human capacity is very important to preserve his life and it is the most important part of his dignity.

Rousseau's famous words are that human beings have "the faculty of self-improvement" [5]. With these words, he wanted to explain that this is the faculty which distinguished human beings from animal. Unlike other living creatures which have a fixed (certain) way of life, nature (and God) does not provide a human being a fixed way of life that has to be followed. In front of human beings, there are many choices that can be chosen freely. The free choices that a human being makes have the capacity to change, to improve, and to search for a new way of life. In this way, human beings experience an unending progress toward perfection.

Further, Rousseau said, "However, even if the difficulties attending all these questions should still leave room for difference in this respect between men and brutes, there is another very specific quality which distinguishes them, and which will admit of no dispute. This is the faculty of selfimprovement, which, by the help of circumstances, gradually develops all the rest of our faculties, and is inherent in the species as in the individual: whereas a brute is, at the end of a few months, all he will ever be during his whole life, and his species, at the end of a thousand years, exactly what it was the first year of that thousand. Why is man alone liable to grow 
into a dotard?" [5].

According to Rousseau the faculty of self-improvement is inherent in the human species and in the individual. With the help of circumstances, self-improvement will enable the development of all human faculties. Since self-improvement is inherent in the human species, it is natural that human beings always capable of self-improvement. In the modern terminology, human beings are always self-enhancing. It is embedded in the very nature of human being so that it will happen naturally and done by nature.

So, human enhancement is part of human nature and even part of human identity. As free and rational creature, human beings have capability of radically changing its nature through the imitation of other creatures or the members of its own species. The human enhancement is the capacity to learn and thereby to find new and better means to satisfy needs. It means that not all human enhancements should be questioned. Natural enhancement-without doubt-can be accepted morally since it is part of human nature.

For Rousseau JJ, et al. [5], natural human enhancement is good, and we cannot deny. So, what is natural? To answer this question, it is better to turn to Aristotle. In his book Politic II, he said, "Not in depraved things but in those well oriented according to nature, and is we to consider what is natural." The naturalness of a thing depends on its orientation toward nature. For Aristotle, "what is natural is better than what is acquired" (Aristotle, Rhetoric I, 27).
A car accident happened and paralyzes the driver and minimizes his capability to communicate. There is a device, designed to improve his communication skills. It is highly profitable for the disable. Is it enhancement or therapy? According to Rousseau and Aristotle, it is neither therapy nor enhancement, but this device makes natural communication works. It is acceptable morally. It sustains and fortify human nature and human dignity. It makes human nature functioning well.

\section{References}

1. Talbot M (2012) Bioethics: An introduction, Cambridge University Press, pp: 253.

2. Giubilini A, Sanyal S (2016) Challenging Human Enhancement". In: Clarke S, et al. (Eds.), The Ethics of Human Enhancement: Understanding the Debate, Oxford University Press, Oxford, pp: 1.

3. Buchanan A (2011) Beyond Humanity: The Ethics of Biomedical Enhancement, Oxford university Press, Oxford, pp: 23.

4. Harold WB, Timothy KC (2005) Is human nature obsolete? Genetics, bioengineering, and the future of the human condition. Massachusetts Institute of Technology, Cambridge, pp: 213.

5. Rousseau JJ (1987) Discourse on the Origin and Foundations of Inequality among Men, Hackett Publishing Company, Cambridge, pp: 34-45. 